\title{
Depression and the relationship between sleep disturbances, nightmares, and suicidal ideation in treatment-seeking Canadian Armed Forces members and veterans
}

\author{
J. Don Richardson ${ }^{1,2,3^{*}}$ (D), Lisa King ${ }^{1}$, Kate St. Cyr ${ }^{1}$, Philippe Shnaider ${ }^{3,4}$, Maya L. Roth ${ }^{1,5}$, Felicia Ketcheson ${ }^{1}$, \\ Ken Balderson ${ }^{1,6}$ and Jon D. Elhai ${ }^{7}$
}

\begin{abstract}
Background: Research on the relationship between insomnia and nightmares, and suicidal ideation (SI) has produced variable findings, especially with regard to military samples. This study investigates whether depression mediated the relationship between: 1) sleep disturbances and $\mathrm{SI}$, and 2) trauma-related nightmares and $\mathrm{Sl}$, in a sample of treatmentseeking Canadian Armed Forces (CAF) personnel and veterans ( $N=663)$.

Method: Regression analyses were used to investigate associations between sleep disturbances or trauma-related nightmares and SI while controlling for depressive symptom severity, posttraumatic stress disorder (PTSD) symptom severity, anxiety symptom severity, and alcohol use severity. Bootstrapped resampling analyses were used to investigate the mediating effect of depression.
\end{abstract}

Results: Approximately two-thirds of the sample (68\%; $N=400)$ endorsed sleep disturbances and $88 \%(N=516)$ reported experiencing trauma-related nightmares. Although sleep disturbances and trauma-related nightmares were both significantly associated with $\mathrm{SI}$ on their own, these relationships were no longer significant when other psychiatric conditions were included in the models. Instead, depressive symptom severity emerged as the only variable significantly associated with $\mathrm{SI}$ in both equations. Bootstrap resampling analyses confirmed a significant mediating role of depression for sleep disturbances.

Conclusions: The findings suggest that sleep disturbances and trauma-related nightmares are associated with SI as a function of depressive symptoms in treatment-seeking CAF personnel and veterans. Treating depression in patients who present with sleep difficulties may subsequently help mitigate suicide risk.

Keywords: Major depressive disorder, Suicide, Posttraumatic stress disorder, Insomnia, Nightmares, Canadian armed forces

\footnotetext{
* Correspondence: don.richardson@sjhc.london.on.ca

${ }^{1}$ Parkwood Institute Operational Stress Injury Clinic, London, ON, Canada

${ }^{2}$ Department of Psychiatry, Western University, London, ON, Canada

Full list of author information is available at the end of the article
}

(c) The Author(s). 2018 Open Access This article is distributed under the terms of the Creative Commons Attribution 4.0 International License (http://creativecommons.org/licenses/by/4.0/), which permits unrestricted use, distribution, and reproduction in any medium, provided you give appropriate credit to the original author(s) and the source, provide a link to the Creative Commons license, and indicate if changes were made. The Creative Commons Public Domain Dedication waiver (http://creativecommons.org/publicdomain/zero/1.0/) applies to the data made available in this article, unless otherwise stated. 


\section{Background}

Sleep problems such as insomnia, nightmares, and poor sleep quality are frequently reported among military members and veterans [1]. Recent research employing data from the Deployment Life Study [2] reported that nearly half of interviewed US service members (48.6\%) exceeded clinically-significant thresholds for sleep disturbances [1]. In a sample of veterans returning from Iraq or Afghanistan, Plumb and colleagues [3] reported that $89.1 \%$ met the cut off score for "poor sleep" using the Pittsburgh Sleep Quality Index. Similarly, high rates of sleep problems were found among a sample of Canadian veterans seeking treatment for mental-health conditions, with reported rates as high as $87 \%$ for trouble falling asleep, and $68 \%$ for experiencing nightmares [4]. Insomnia often serves as the initial reason military personnel seek medical treatment, and remains one of the most frequently reported complaints of treatment-seeking military members and veterans $[5,6]$.

This finding is largely unsurprising, given both the physical and emotional demands of an occupation in the military, and that sleep problems are a core symptom of numerous psychiatric disorders. For example, sleep disturbances are symptoms of both posttraumatic stress disorder (PTSD) and major depressive disorder (MDD) [7]. In one study, veterans with PTSD reported more impaired sleep as measured by the Pittsburgh Sleep Quality Inventory than veterans without PTSD [8]. Additionally, numerous research studies have identified a relationship between sleep-related difficulties and suicidal ideation (SI), suicide attempts, and completed suicide in both military and civilian populations [9-21], though the nature of the relationship between psychiatric conditions, sleep difficulties, and SI is complex and not fully understood.

Some research suggests that the relationship between sleep disturbances and SI is best explained by the presence of psychiatric diagnoses (i.e., there is an indirect effect of sleep disturbance on SI). For example, Bernert and colleagues [11] and Liu [22] both found that the relationship between nightmares and suicidal behaviours was statistically significant even when accounting for depression. Richardson and colleagues [4] found that, when controlling for probable diagnoses of PTSD, MDD, generalized anxiety disorder (GAD), and alcohol use disorder (AUD) in a sample of treatment-seeking CAF members and veterans, only probable MDD emerged as a significant predictor of SI. Similarly, Bryan and colleagues [23] found that depression significantly mediated the relationship between insomnia severity and suicide risk in three clinical samples of military personnel. In contrast, evidence suggesting that sleep disturbances have a direct effect on suicidal behaviours also exists. This position asserts that the relationship between sleep disturbances and SI is not accounted for by psychiatric conditions, but that sleep-related difficulties represent an independent risk factor for suicidal behaviours. For example, Ribeiro and colleagues [19] found that insomnia symptoms outperformed a number of other variables such as depression, hopelessness, PTSD, anxiety, and alcohol abuse in predicting SI using a cross-sectional and longitudinal design. After adjusting for mental health and substance use symptoms, Pigeon and colleagues [24] found that time to completed suicide was influenced by sleep problems, such that veterans who complained of sleep difficulties died by suicide sooner than those who did not.

As the number of military personnel suffering from psychiatric conditions such as PTSD and MDD [25-27], and rates of completed suicide [28-32] continue to rise, not only is it important to discern risk factors for suicidal behaviours, but also how these risk factors exert their effects (i.e., directly or indirectly). Such research is critical in order to better inform treatment initiatives, especially given the complexity of treating military members presenting with comorbid mental health conditions [33]. If sleep problems directly impact SI beyond the effect of psychiatric conditions, specific and targeted interventions for sleep may, in turn, reduce risk of SI. However, if the relationship between sleep and SI is mediated by psychiatric diagnoses, such as depression, targeting only specific sleep symptoms may provide little in the way of attenuating risk of SI.

Given the mixed results obtained in previous research, the aim of the current study was to further investigate the relationship between sleep disturbances (i.e., difficulty falling or staying asleep), trauma-related nightmares, and SI in a sample of treatment-seeking CAF members and veterans.

\section{Method \\ Participants and procedure}

Participants were treatment-seeking CAF members and veterans presenting to a specialized outpatient mental health clinic for military service-related psychiatric conditions. All measures were administered as part of a standardized intake protocol. Informed consent to use intake data for research and program evaluation was obtained from participants at the time of their initial clinical assessment. Once consent was obtained, data were de-identified and stored in an electronic database. The present study used previously-collected intake data from $663 \mathrm{CAF}$ members and veterans presenting to the clinic between April 2004 and September 2014. Individuals who were referred to the clinic more than one time during this period were included in the study only once (e.g., any subsequent referrals were not included). Ethical approval was received from Western University and relevant hospital review boards. 


\section{Measures}

The Patient Health Questionnaire (PHQ) is a self-administered version of the Primary Care Evaluation of Mental Disorders (PRIME-MD) used to evaluate mood, anxiety, and somatoform disorders [34]. Symptoms of depression were measured using the PHQ-9, a nine-item measure used to evaluate depressive symptom severity based on DSM-IV diagnostic criteria. Respondents indicated how frequently they experienced each symptom in the past two weeks on a scale ranging from $0=$ "Not at all" to 3 = "Nearly every day." Responses were summed to provide a total score ranging from 0 to 27 , where higher scores are indicative of greater depressive symptom severity [35].

SI was measured using a single item from the PHQ-9: "Thoughts that you would be better off dead or hurting yourself in some way." This item has been used as a measure of SI in previous research $[4,36]$. To reduce the potential for artificially inflated relationships among depressive symptom severity, sleep disturbances, and SI, two items, one assessing SI, and the other assessing sleep disturbances, were removed from PHQ-9 depressive symptom severity scores. Internal consistency of the PHQ-9 with and without these items was good (Cronbach's alpha $=0.89$ and 0.87 , respectively).

PTSD symptom severity was measured using the PTSD Checklist - Military version (PCL-M) [37]. The PCL-M is a 17-item, self-administered questionnaire measuring PTSD symptom severity specific to a military-related trauma. Respondents were asked to indicate how much they had been affected by each symptom over the past month using a scale ranging from $1=$ "Not at all" to $5=$ "Extremely." Responses were summed to provide a total score ranging from 17 to 85, where higher scores indicate greater PTSD symptom severity. Consistent with previous research studies and recommendations [37], a cut-off score of 50 was used to establish the presence of "probable" PTSD.

Sleep disturbances and trauma-related nightmares were measured using individual items from the PCL-M. The item assessing sleep disturbances asked participants to indicate how often they had trouble falling and staying asleep; the item assessing nightmares asked participants to indicate how often they experienced disturbing dreams of a stressful military experience. Both of these items have been used in previous research to examine sleep disturbances and nightmares [4]. In order to reduce the potential for artificially inflating the relationship between sleep disturbances, trauma-related nightmares, and PTSD symptom severity, these items were removed from PCL-M scores. Internal consistency of the PCL-M with and without the items on sleep disturbance and nightmares was excellent (Cronbach's alpha $=0.93$ and 0.92 , respectively).
Alcohol use was measured using the Alcohol Use Disorders Identification Test (AUDIT): a 10-item, self-report questionnaire identifying harmful alcohol use behaviours and dependence [38]. Responses were summed to provide a total score ranging from 0 to 40 , where higher scores indicate more problematic alcohol use behaviours. A score of 8 or higher is typically used to signify a potential alcohol use problem [38, 39]. Internal consistency of the AUDIT in the current sample was good (Cronbach's alpha $=0.88$ ).

Table 1 Descriptive statistics

\begin{tabular}{|c|c|c|}
\hline Categorical Variable & $n$ & $\%$ \\
\hline \multicolumn{3}{|l|}{ Deployment locales } \\
\hline Afghanistan & 117 & 31.0 \\
\hline Balkan States (former Yugoslovia, Kosovo, etc.) & 133 & 35.2 \\
\hline Domestic deployment & 125 & 33.1 \\
\hline Africa (Somalia, Rwanda, Sierra Leone, etc). & 45 & 11.9 \\
\hline \multicolumn{3}{|l|}{ Education $(N=574)$} \\
\hline Less than high school & 113 & 19.7 \\
\hline Completed high school & 179 & 31.2 \\
\hline Some college/university & 159 & 27.7 \\
\hline Completed college/university & 123 & 21.4 \\
\hline \multicolumn{3}{|l|}{ Marital status $(N=574)$} \\
\hline Married/living with partner & 325 & 56.6 \\
\hline Divorced/separated & 125 & 21.8 \\
\hline Single (never married) & 109 & 19.0 \\
\hline Widowed & 15 & 2.6 \\
\hline \multicolumn{3}{|l|}{ Sleep Disturbances $(N=588)$} \\
\hline Not at all/ a little bit & 188 & 32.0 \\
\hline Moderately/quite a bit/extremely & 400 & 68.0 \\
\hline \multicolumn{3}{|l|}{ Nightmares $(N=585)$} \\
\hline Not at all/a little bit & 69 & 11.8 \\
\hline Moderately/quite a bit/extremely & 516 & 88.2 \\
\hline \multicolumn{3}{|l|}{ Suicidal Ideation $(N=529)$} \\
\hline Not at all & 290 & 54.8 \\
\hline Some days & 151 & 28.6 \\
\hline More than half the days/nearly every day & 88 & 16.6 \\
\hline $\begin{array}{l}\text { PCL-M criteria met for probable PTSD } \\
(\text { score }>=50 ; N=554)\end{array}$ & 402 & 72.6 \\
\hline $\begin{array}{l}\text { PHQ-9 criteria met for probable MDD } \\
\text { (score }>=10 ; N=522)\end{array}$ & 413 & 79.1 \\
\hline Measure & Mean & $S D$ \\
\hline PCL-M & 57.71 & 14.78 \\
\hline PHQ-9 & 15.85 & 6.60 \\
\hline GAD & 10.06 & 3.40 \\
\hline AUDIT & 8.06 & 8.09 \\
\hline
\end{tabular}

Note. PCL-M Posttraumatic Stress Disorder Checklist - Military Version, PHQ-9 Patient Health Questionnaire-9, AUDIT Alcohol Use Disorders Identification Test, GAD Generalized Anxiety Disorder section of the PHQ 
Anxiety symptoms were measured using the GAD-7 module of the PHQ [34]. Respondents were asked to rate how often in the past two weeks they experienced each of seven symptoms on a scale ranging from $0=$ "Not at all" to 2 = "More than half the days." Responses were summed to provide a total score ranging from 0 to 14, where higher scores indicate greater anxiety. Internal consistency of these seven items in the current sample was excellent (Cronbach's alpha $=0.94)$.

\section{Statistical analyses}

SPSS Statistics v. 23.0 (Chicago, IL) was used for all analyses. Correlations between all variables were examined. Associations between sleep disturbances and SI, and nightmares and SI, were first investigated in two steps. Step 1 examined whether each variable (sleep disturbances or nightmares) was associated with SI using univariate linear regression. In Step 2, PHQ-9, PCL-M, AUDIT, and GAD-7 severity scores were added to each model.

To test whether the effects of sleep disturbances and trauma-related nightmares on SI were mediated by psychiatric conditions, we used the bootstrapping method with bias-corrected confidence estimates proposed by Preacher and Hayes [40]. Simulation studies have shown good accuracy and power in detecting mediation effects using this approach [41]. The 95\% confidence intervals (CIs) for indirect effects were examined, and 5000 bootstrap resamples were used for each. CIs that do not cross zero indicate a significant mediating effect. Age, sex, level of education, and marital status were entered into the models as covariates.

\section{Results}

The vast majority of participants were male $(N=546$; $91.0 \%)$, and the mean age was 44.6 years $(S D=13.98)$.
Participants served an average 13.78 years $(S D=9.26)$ and had been deployed 2.55 times on average $(S D=$ 9.26). Most participants were veterans of the CAF $(N=$ 546; 82.4\%); the remaining participants were still actively serving $(N=117 ; 17.6 \%)$. Table 1 presents the means and standard deviations for each measure, as well as frequencies for sleep disturbances, trauma-related nightmares, SI, and deployment locations for the 378 participants who were deployed.

The majority of participants (68\%) indicated they had trouble falling or staying asleep at a severity of "moderately or greater," whereas $88 \%$ of our sample indicated they experienced trauma-related nightmares at a severity of "moderately or greater." Nearly half of participants (45.2\%) endorsed experiencing SI at least some days. On average, participants had moderately severe depression and most met screening criteria for probable PTSD (see Table 1).

Correlation analyses revealed significant associations between SI and PTSD symptom severity, depressive symptom severity, trauma-related nightmares, sleep disturbances, and anxiety symptom severity. Severity of alcohol use was not significantly correlated with SI, and was thus omitted from further analyses (see Table 2).

As expected, based on significant univariate correlations, sleep disturbances and nightmares were both significantly associated with SI. However, after adding the PTSD, depression, and anxiety symptom severity variables, neither the relationship between sleep disturbances and SI, nor nightmares and SI, remained significant. Instead, depressive symptom severity emerged as the only variable significantly associated with SI in both cases (see Table 3). Variation inflation factors did not indicate any issues with multicollinearity.

In the first model, sleep disturbances were significantly associated with SI $(\mathrm{b}=.215, \mathrm{SE}=.035, p<.001)$. Using

Table 2 Correlations

\begin{tabular}{|c|c|c|c|c|c|c|c|c|c|c|c|}
\hline Variable & 1 & 2 & 3 & 4 & 5 & 6 & 7 & 8 & 9 & 10 & 11 \\
\hline 1. SI & & $.406^{* * *}$ & $.529^{* * *}$ & $.172^{* *}$ & $.272^{* *}$ & .073 & $.382^{* *}$ & .039 & .052 & .025 & -.080 \\
\hline 2. PCL-M & & & $.688^{* * *}$ & $.593^{* * *}$ & $.546^{* *}$ & $.128^{* *}$ & $.584^{* *}$ & -.012 & -.010 & $-.095^{*}$ & -.064 \\
\hline 3. $\mathrm{PHQ}-9$ & & & & $.345^{* *}$ & $.520^{* *}$ & .033 & $.677^{* *}$ & -.031 & .028 & -.048 & -.053 \\
\hline 4. Nightmares & & & & & $.375^{* *}$ & .059 & $.234^{* *}$ & .043 & -.059 & -.024 & -.016 \\
\hline 5. Sleep disturbances & & & & & & $.105^{*}$ & $.482^{* *}$ & -.027 & .012 & .008 & -.053 \\
\hline 6. AUDIT & & & & & & & .082 & $-.106^{*}$ & $-.086^{*}$ & $.118^{* *}$ & -.039 \\
\hline 7. GAD & & & & & & & & -.012 & .031 & -.081 & -.052 \\
\hline 8. Age & & & & & & & & & -.071 & $-.186^{* *}$ & $-.100^{*}$ \\
\hline 9. Sex & & & & & & & & & & .070 & $.169^{* *}$ \\
\hline 10. Marital status & & & & & & & & & & & $.087^{*}$ \\
\hline 11. Level of education & & & & & & & & & & & \\
\hline
\end{tabular}

Note. SI Suicidal ideation, PCL-M Posttraumatic Stress Disorder Checklist - Military Version, PHQ-9 Patient Health Questionnaire-9, AUDIT Alcohol Use Disorders Identification Test, GAD Generalized Anxiety Disorder section of the PHQ

${ }^{*} p<.05,{ }^{* *} p<.01,{ }^{* * *} p<.001$ 
Table 3 Regression analyses examining associations between sleep disturbances, nightmares and suicidal ideation

\begin{tabular}{llll}
\hline Nightmares & SI & Sleep Disturbances & SI \\
\hline Step 1 & \multicolumn{3}{c}{ Step 1 } \\
Nightmares & $.312^{* *}$ & Sleep disturbances & $.219^{* * *}$ \\
Step 2 & \multicolumn{3}{c}{ Step 2 } \\
Nightmares & .001 & Sleep disturbances & -.253 \\
Anxiety (GAD-7) & .007 & Anxiety (GAD-7) & .009 \\
PTSD (PCL-M) & .002 & PTSD (PCL-M) & .003 \\
Depression (PHQ-9) & $.083^{* * *}$ & Depression (PHQ-9) & $.084^{* * *}$
\end{tabular}

Note. SI Suicidal ideation, PCL-M Posttraumatic Stress Disorder Checklist Military Version, PHQ-9 Patient Health Questionnaire-9, GAD Generalized Anxiety Disorder section of the PHQ

Note: Presented are unstandardized beta coefficients

${ }^{* *} p=<.01,{ }^{* * *} p<.001$

Preacher and Hayes' 2004 bootstrapping method, depressive symptom severity was found to significantly mediate the relationship between sleep disturbances and SI [bootstrapped unstandardized indirect effect $=0.221$; CI $(0.175,0.279)]$ (Fig. 1). In the second model, nightmares were significantly associated with SI $(b=.109$, $\mathrm{SE}=.031, p<.001)$. Similarly, depressive symptom severity was also found to significantly mediate the relationship between trauma-related nightmares and SI [bootstrapped unstandardized indirect effect $=0.136$; CI (0.101, 0.177)] (Fig. 2).

\section{Discussion}

The current study found that depressive symptom severity significantly mediated the relationship between sleep disturbances and SI, as well as the relationship between trauma-related nightmares and SI, in a sample of mental health treatment-seeking CAF members and veterans. These findings suggest that MDD should be treated as an independent risk factor for SI.

More than two thirds of our treatment-seeking sample of CAF members and veterans reported being at least moderately bothered by sleep disturbances; and almost 90\% reported being at least moderately bothered by trauma-related nightmares. Congruent with previous research, these findings emphasize that sleep difficulties are a common concern for military personnel and veterans $[42,43]$, and echo the recent findings of Creamer and colleagues [44], who found that trauma-related nightmares were common amongst a cohort of 500 active duty United States military personnel. Our results also revealed that although sleep disturbances and nightmares were significantly associated with SI on their own, these associations seem to be mediated by depressive symptom severity, which is consistent with previous research supporting an indirect role of sleep disturbance $[4,23]$. However, unlike prior research [4], we did not find the association between trauma-related nightmares and SI to be mediated by PTSD.

Unfortunately, there are currently few evidence-based practices to prevent and treat sleep difficulties among military members [1]. One promising therapy is Cognitive Behavioural Therapy for Insomnia (CBT-I). Recently, Trockel and colleagues [45] found that CBT-I was associated with reductions in the odds of SI and depressive symptoms in their sample of veterans presenting for insomnia treatment. Further, a systematic review by Taylor and Pruiksma [46] found support for CBT-I as a viable psychotherapeutic modality for the treatment of comorbid insomnia and psychiatric disorders. Exposure,
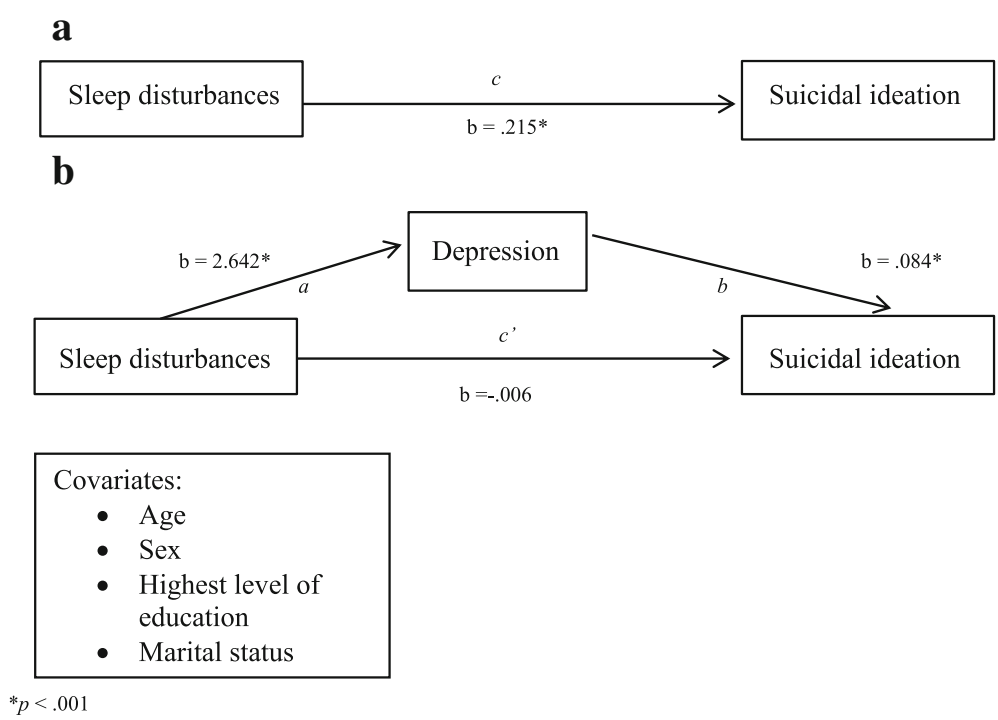

Fig. 1 Association (a) and Mediation model for sleep disturbances and suicidal ideation (b) 


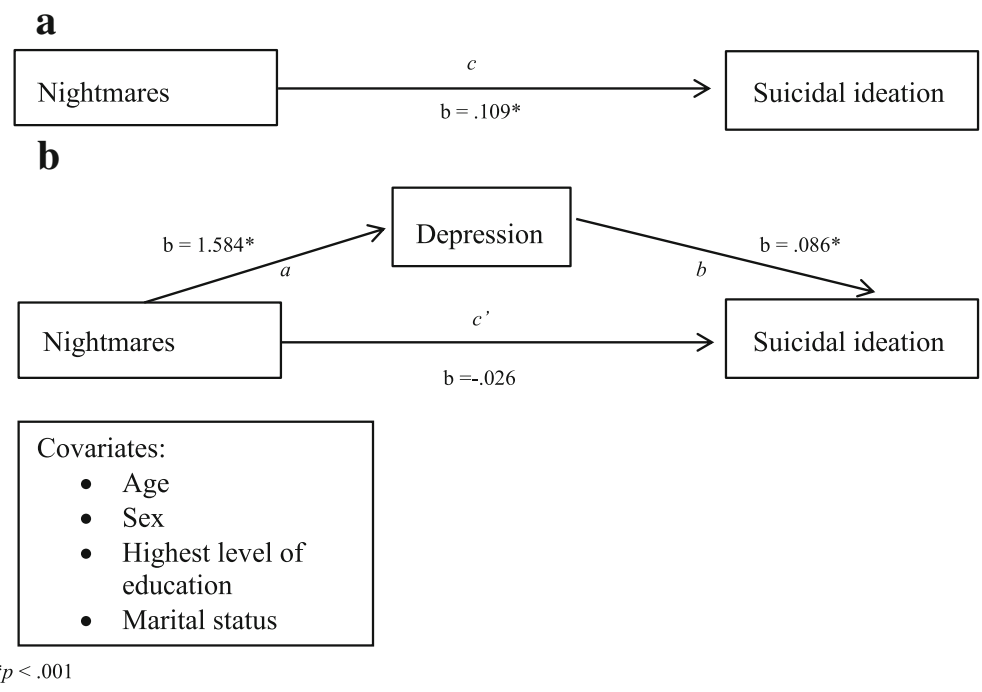

Fig. 2 Association (a) and Mediation model for nightmares and suicidal ideation (b)

Relaxation, and Rescripting Therapy adapted for military members (ERRT-M) has also shown some initially promising results. In their small $(N=19)$ pilot study of trauma-exposed veterans, Bailliett and colleagues [47] found that improvements in nightmare frequency, depression severity, sleep quality, and insomnia severity were achieved one week into ERRT-M therapy, and maintained 2 months later.

Results should be interpreted with caution in light of the following limitations. We relied on cross-sectional data obtained from a treatment-seeking population composed primarily of CAF veterans. As such, we cannot evaluate causal relationships between sleep disturbances, nightmares, and SI; and results may not be generalizable to other military, veteran, or clinical populations. Single-item measures were used to assess SI, sleep disturbances, and trauma-related nightmares. The sleep disturbances item combines difficulty initiating sleep and staying asleep. It is plausible that there are unique challenges associated with difficulty falling vs. staying asleep. Similarly, there may be differences between disturbing dreams and nightmares that cause one to arouse from their sleep that were not captured as a result of the language used in this single item. Lastly, the item used to assess SI ideation does not clearly distinguish between suicidal thought and non-suicidal self-injury. Additionally, because these single-item indicators were removed from the PHQ-9 and PCL-M to control for inflation, we essentially examined a version of depressive symptom severity that did not include sleep disturbances and SI, and a version of PTSD symptom severity that did not include sleep disturbances and nightmares. Although this approach has been used in previous research [4], findings might not accurately depict the clinical presentation of depression and PTSD among military personnel and veterans.

\section{Conclusion}

The results from the present study contribute to furthering our understanding of the relationship between sleep disturbances, trauma-related nightmares, and SI in the presence of other mental health diagnoses. Findings implicate depression symptom severity as the greatest risk factor for SI, emphasizing the importance of targeting depression to mitigate suicide risk within military personnel and veterans. Incorporating therapies that target sleep and trauma-related nightmares into the management of depression and PTSD may provide additional therapeutic benefit and, consequently, further diminish the risk of SI. Treatment of psychiatric comorbidities, such as depression and sleep disturbances, may be especially crucial in reducing risk of SI in treatment-seeking military populations, particularly since previous research shows that individuals with military related-PTSD may experience poorer treatment response compared to their civilian counterparts [6]. Continued research examining the relationship between sleep disturbances, nightmares, and SI within varying clinical populations, especially at the meta-analysis level, may shed additional light on the direct and indirect effects of sleep-related variables.

\section{Abbreviations}

AUD: Alcohol use disorder; CAF: Canadian Armed Forces; CBT-I: Cognitive behavioural therapy for insomnia; CFMHS: Canadian Forces Mental Health Survey; DSM-IV: Diagnostic and Statistical Manual of the American Psychiatric Association, Fourth Edition; ERRT-M: Exposure, Relaxing, and Rescripting Therapy for military; GAD: Generalized anxiety disorder; MDD: Major depressive disorder; 
PCL-M: PTSD Checklist, Military version; PHQ: Patient Health Questionnaire; PTSD: Posttraumatic stress disorder; SI: Suicidal ideation

\section{Availability of data and materials}

The dataset used in this study are available from the corresponding author upon reasonable request, and pending approval from the HSREB at Western University and the LHRI.

\section{Authors' contributions}

DR: Contributed to the conception and design, drafting of the manuscript, and critical revision. LK: Contributed to conception and design, data analysis and interpretation, drafting of the manuscript, and critical revision. KS: Contributed to conception and design, data analysis and interpretation, drafting of the manuscript, and critical revision. PS: Contributed to conception and design, and critical revision. MR: Contributed to conception and design, and critical revision. FK: Contributed to conception and design, and critical revision. KB: Contributed to conception and design, and critical revision. JE: Contributed to conception and design, and critical revision. All authors read and approved the final manuscript.

\section{Ethics approval and consent to participate}

This research was approved by the Health Sciences Research Ethics Board at Western University, as well as the Lawson Health Research Institute. All participants provided written informed consent for their data to be included in the study.

\section{Consent for publication}

N/A

\section{Competing interests}

The authors declare that they have no competing interests.

\section{Publisher's Note}

Springer Nature remains neutral with regard to jurisdictional claims in published maps and institutional affiliations.

\section{Author details}

${ }^{1}$ Parkwood Institute Operational Stress Injury Clinic, London, ON, Canada. 2Department of Psychiatry, Western University, London, ON, Canada. ${ }^{3}$ Department of Psychiatry and Behavioural Neurosciences, McMaster University, Hamilton, ON, Canada. ${ }^{4}$ Anxiety Treatment and Research Centre, St. Joseph's Healthcare Hamilton, Hamilton, ON, Canada. ${ }^{5}$ Department of Graduate Studies, Ryerson University, Toronto, ON, Canada. ${ }^{6}$ Department of Psychiatry, University of Toronto, Toronto, ON, Canada. ${ }^{7}$ Departments of Psychology and Psychiatry, University of Toledo, Toledo, $\mathrm{OH}$, USA

Received: 26 February 2018 Accepted: 11 June 2018

\section{Published online: 19 June 2018}

\section{References}

1. Troxel WM, Shih RA, Pedersen E, Geyer L, Fisher MP, Griffin BA, et al. Sleep in the Military: Promoting Healthy Sleep Among U.S. Servicemembers. Santa Monica, CA: RAND Corporation; 2015

2. Tanielian T, Karney BR, Chandra A, Meadows SO. The deployment life study: methodological overview and baseline sample description. Santa Monica, CA: RAND Corporation; 2014

3. Plumb TR, Peachey JT, Zelman DC. Sleep disturbance is common among servicemembers and veterans of operations enduring freedom and Iraqi freedom. Psychol Serv. 2014:11(2):209-19.

4. Richardson JD, St Cyr K, Nelson C, Elhai JD, Sareen J. Sleep disturbances and suicidal ideation in a sample of treatment-seeking Canadian forces members and veterans. Psychiatry Res. 2014;218(1-2):118-23.

5. Maher MJ, Rego SA, Asnis GM. Sleep disturbances in patients with posttraumatic stress disorder: epidemiology, impact and approaches to management. CNS Drugs. 2006;20(7):567-90.

6. Rosen C, Adler $\mathrm{E}$, Tiet Q. Presenting concerns of veterans entering treatment for posttraumatic stress disorder. J Trauma Stress. 2013;26(5):640-3.

7. American Psychiatric Association. Diagnostic and Statistical Manual of Mental Disorders (5th ed.). Arlington, VA: American Psychiatric Publishing; 2013.

8. Pietrzak RH, Morgan CA 3rd, Southwick SM. Sleep quality in treatmentseeking veterans of operations enduring freedom and Iraqi freedom: the role of cognitive coping strategies and unit cohesion. J Psychosom Res. 2010:69(5):441-8

9. Agargun MY, Kara H, Solmaz M. Sleep disturbances and suicidal behavior in patients with major depression. J Clin Psychiatry. 1997:58(6):249-51.

10. Bernert RA, Joiner TE. Sleep disturbances and suicide risk: a review of the literature. Neuropsychiatr Dis Treat. 2007;3(6):735-43.

11. Bernert RA, Joiner TE Jr, Cukrowicz KC, Schmidt NB, Krakow B. Suicidality and sleep disturbances. Sleep. 2005;28(9):1135-41.

12. Bernert RA, Kim SJ, Iwata NG, Perlis ML. Sleep disturbances as an evidencebased suicide risk factor. Curr Psychiatry Rep. 2015;17(15):1-9.

13. Chakravorty S, Grandner MA, Mavandai S, Perlis LM, Sturgis BE, WD O. Suicidal ideation in veterans misuising alcohol: relationships with insomnia symptoms and sleep duration. Addict Behav. 2014;39:399-405.

14. Dell'Osso L, Massimetti G, Conversano C, Bertelloni CA, Carta MG, Ricca V, Carmassi C. Alterations in circadian/seasonal rhythms and vegetative functions are related to suicidality in DSM-5 PTSD. BMC Psychiatry. 2014;14(1):352.

15. Krakow B, Artar A, Warner TD, Melendrez D, Johnston L, Hollifield M, Koss M Sleep disorder, depression, and suicidality in female sexual assault survivors. Crisis. 2000;21(4):163-70.

16. Malik S, Kanwar A, Sim LA, Prokop LJ, Wang Z, Benkhadra K, Murad MH. The association between sleep disturbances and suicidal behaviors in patients with psychiatric diagnoses: a systematic review and meta-analysis. Syst Rev. 2014;3:18.

17. Nadorff MR, Ellis TE, Allen GJ, Winer ES, Herra S. Presence and persistence of sleep-related symptoms and suicidal ideation in psychiatric inpatients. Crisis. 2014;35(6):398-405.

18. Nock MK, Deming CA, Fullerton CS, Gilman SE, Goldenberg M, Kessler RC, Ursano RJ. Suicide among soldiers: a review of psychosocial risk and protective factors. Psychiatry. 2013;76(2):97-125.

19. Ribeiro JD, Pease JL, Gutierrez PM, Silva C, Bernert RA, Rudd MD, Joiner TE Jr. Sleep problems outperform depression and hopelessness as cross-sectional and longitudinal predictors of suicidal ideation and behavior in young adults in the military. J Affect Disorders. 2012:136(3):743-50.

20. Sjostrom N, Hetta J, Waern M. Persistent nightmares are associated with repeat suicide attempt: a prospective study. Psychiatry Res. 2009:170(2-3):208-11.

21. Tanskanen A, Tuomilehto J, Viinamaki H, Vartiainen E, Lehtonen J, Puska P. Nightmares as predictors of suicide. Sleep. 2001;24(7):844-7.

22. Liu X. Sleep and adolescent suicidal behavior. Sleep. 2004;27(7):1351-8.

23. Bryan CJ, Gonzales J, Rudd MD, Bryan AO, Clemans TA, Ray-Sannerud B, Etienne N. Depression mediates the relation of insomnia severity with suicide risk in three clinical samples of U.S. military personnel. Depress Anxiety. 2015;32(9):647-55.

24. Pigeon WR, Britton PC, Ilgen MA, Chapman B, Conner KR. Sleep disturbance preceding suicide among veterans. Am J Public Health. 2012;102(Suppl 1):S93-7.

25. Armed Forces Health Surveillance Center. Medical surveillance monthly report (MSMR). In: Armed forces health surveillance center; 2014

26. Castro CA, Kintzle S. Suicides in the military: the post-modern combat veteran and the Hemingway effect. Curr Psychiatry Rep. 2014;16(8):1-9.

27. Pearson C, Zamorski M, \& Jan T. Mental health of the Canadian Armed Forces. Ottawa: Statistics Canada. 2014. http://www.statcan.gc.ca/pub/82624-x/2014001/article/14121-eng.htm. Accessed 15 Jan 2018.

28. Harrell MC, \& Berglass N. Losing the battle: the challenge of military suicide. Policy brief. Washington, DC; 2011.

29. McCarthy M. Suicide rates double among US soldiers between 2004 and 2009, research shows. BMJ. 2014;348:g1987.

30. Thompson JM, Zamorski MA, Sweet J, VanTil L, Sareen J, Pietrzak RH, Pedlar D. Roles of physical and mental health in suicidal ideation in Canadian Armed Forces regular force veterans. Can J Public Health. 2014;105(2):e109-15.

31. Ursano RJ. Suicide: a national health challenge, an army health threat Psychiatry. 2013;76(2):95-6.

32. Ursano RJ, Heeringa SG, Stein MB, Jain S, Raman R, Sun X, et al. Prevalence and correlates of suicidal behavior among new soldiers in the U.S. Army: results from the army study to assess risk and resilience in service members (army Starrs). Depress Anxiety. 2015;32(1) https://doi.org/10.1002/da.22317.

33. Richardson JD, Contractor A, Armour C, St Cyr K, Elhai JD, Sareen J. Predictors of long-term treatment outcome in combat and peacekeeping veterans with military-related PTSD. J Clin Psychiatry. 2014;75(11):1299-305.

34. Spitzer R, Kroenke K, Williams J. Validation and utility of a self-report version of PRIME-MD: the PHO primary care study. Primary care evaluation of mental disorders. Patient health questionnaire. JAMA. 1999;282(18):1737-44. 
35. Kroenke K, Spitzer R, Williams J. The PHQ-9: validity of a brief depression severity measure. J Gen Intern Med. 2001;16(9):606-13.

36. Nelson C, St. Cyr K, Corbett B, Hurley E, Gifford S, Elhai JD, et al. Predictors of posttraumatic stress disorder, depression, and suicidal ideation among Canadian forces personnel in a national Canadian military health survey. J Psychiatr Res. 2011:45(11):1483-8.

37. Weathers F, Litz B, Herman D, Huska J, \& Keane T. The PTSD Checklist (PCL): Reliability, validity, and diagnostic utility. Paper presented at the Annual Convention of the International Society for Traumatic Stress Studies, San Antonio, TX; 1993.

38. Babor TF, Biddle-Higgins JC, Saunders JB, Monteiro MG. AUDIT: the alcoho use disorders identification test: guidelines for use in primary health care. Geneva: World Health Organization; 2001.

39. Saunders J, Aasland O, Barbor T, de la Fuente JR, Grant M. Development of the alcohol use disorders identification test: WHO collaborative project on early detection of persons with harmful alcohol consumption - II. Addiction. 1993;88(6):791-804.

40. Preacher KJ, Hayes AF. SPSS and SAS procedures for estimating indirect effects in simple mediation models. Behav Res Methods Instrum Comput. 2004;36(4):717-31.

41. Williams J, Mackinnon DP. Resampling and distribution of the product methods for testing indirect effects in complex models. Struct Equ Modeling. 2008;15(1):23-51.

42. Seelig AD, Jacobson IG, Smith B, Hooper TI, Boyko EJ, Gackstetter GD, et al. Sleep patterns before, during, and after deployment to Iraq and Afghanistan. Sleep. 2010;33(12):1615-22.

43. Taylor KM, Hilton MS, Campbell SJ, Beckerly ES, Shobe K, Drummond PAS. Prevalence and mental health correlates of sleep disruption among military members serving in a combat zone. Mil Med. 2014;179(7):744-51.

44. Creamer JL, Brock MS, Matsangas P, Motamedi V, Mysliwiec V. Nightmares in United States military personnel with sleep disturbances. J Clin Sleep Med. 2018;14(3):419-26.

45. Trockel M, Karlin B, Taylor C, Brown G, Manber R. Effects of cognitive behavioral therapy for insomnia on suicidal ideation in veterans. Sleep. 2015:38(2):259-65.

46. Taylor DJ, Pruiksma KE. Cognitive and behavioural therapy for insomnia (CBT-I) in psychiatric populations: a systematic review. Int Rev Psychiatry. 2014;26(2):205-13.

47. Balliett NE, Davis JL, Miller KE. Efficacy of a brief treatment for nightmares and sleep disturbances for veterans. Psychol Trauma. 2015;7(6):507-15.

\section{Ready to submit your research? Choose BMC and benefit from:}

- fast, convenient online submission

- thorough peer review by experienced researchers in your field

- rapid publication on acceptance

- support for research data, including large and complex data types

- gold Open Access which fosters wider collaboration and increased citations

- maximum visibility for your research: over $100 \mathrm{M}$ website views per year

At BMC, research is always in progress.

Learn more biomedcentral.com/submissions 